\title{
Determinação da Cinética Ruminal da Proteína de Vários Alimentos Utilizando o Método de Inibidores In Vitro ${ }^{1}$
}

\author{
Fernando Iván Londoño Hernández ${ }^{2}$, Sebastião de Campos Valadares Filho ${ }^{3}$, Rogério de Paula \\ Lana $^{3}$, Paulo Roberto Cecon ${ }^{4}$, Antonio Bento Mancio ${ }^{3}$, Mario Fonseca Paulino ${ }^{3}$, \\ Karla Alves Magalhães ${ }^{5}$, Sandro Luiz Rosa Reis ${ }^{5}$
}

\begin{abstract}
RESUMO - O objetivo do presente trabalho foi estimar os parâmetros cinéticos da degradação dos compostos nitrogenados de 24 alimentos concentrados e 14 volumosos, por intermédio do método de inibidores in vitro, utilizando-se o sistema Kjeldahl. Foi utilizado líquido ruminal oriundo de bovino recebendo dieta com $60 \%$ de volumoso e $40 \%$ de concentrado. Na preparação de 1000 mL do meio fermentador, utilizaram-se $800 \mathrm{~mL}$ do inóculo, $2 \mathrm{~g}$ de $\mathrm{NaHCO}_{3}$ em $50 \mathrm{~mL}$ de $\mathrm{H}_{2} \mathrm{O}$ destilada, $3,2 \mathrm{~g}$ de pectina em $100 \mathrm{~mL}$ de solução McDougall, 0,234 mL de mercaptoethanol, 0,195 g de sulfato de hidrazina em $25 \mathrm{~mL}$ de solução McDougall e 0,045 g de cloranfenicol em $25 \mathrm{~mL}$ de solução McDougall. Ao meio fermentador adicionaram-se 3,2 g de amido, 3,2 g de xilose e 0,16 mL de antiespumante (Antifoam 204, Sigma Chemical Co. A-6426). Foi determinado o desaparecimento dos compostos nitrogenados dos alimentos nos tempos 0 e 2 horas, incubados na quantidade de, aproximadamente, $1,875 \mathrm{mg}$ de $\mathrm{N}$ para cada tubo de ensaio. As estimativas referentes às taxas de degradação mostraram que os alimentos farelo de glúten de milho, caseína, grão de amendoim moído, cama de frango contendo casca de café como material absorvente e raspa de mandioca possuem proteínas de rápida degradação, observando-se as mais lentas taxas de degradação para o fubá de milho, a farinha de carne e ossos, a cama de frango contendo capim-elefante como material absorvente, a levedura de cana-de-açúcar e a farinha de penas. De maneira geral, os parâmetros da degradação apresentaram resultados semelhantes aos reportados in situ. O método dos inibidores in vitro permitiu uma avaliação rápida e eficiente da cinética de degradação da proteína bruta dos alimentos concentrados. As taxas de degradação de alguns alimentos volumosos foram subestimadas.
\end{abstract}

Palavras-chave: cinética, degradabilidade, inibidor in vitro, nitrogênio

\section{Determination of Ruminal Protein Kinetics of Feedstuffs Using an Inhibitor in vitro Method}

\begin{abstract}
The objective of this work was to evaluate the kinetics parameters of nitrogen compounds degradation for 24 concentrate feedstuffs and 14 grasses, by means of an inhibitor in vitro method, using a Kjeldahl system. Ruminal fluid from steer fed diet with 60:40 forage to concentrate ratio was used. It was used a $800 \mathrm{~mL}$ of ruminal fluid, $2 \mathrm{~g}$ of $\mathrm{NaHCO}_{3}$ in $50 \mathrm{~mL}$ of distilled water, $3.2 \mathrm{~g}$ of pectin in $100 \mathrm{~mL}$ of McDougall, $0.234 \mathrm{~mL}$ of mercaptoethanol and $0.195 \mathrm{~g}$ of hidrazine sulfate in $25 \mathrm{~mL}$ of McDougall and $0.045 \mathrm{~g}$ of chloramphenicol in $25 \mathrm{~mL}$ of McDougall, to prepare $1000 \mathrm{~mL}$ of inoculum. It was added $3.2 \mathrm{~g}$ of starch, $3.2 \mathrm{~g}$ of xylose and $0.16 \mathrm{~mL}$ of Antifoam 204 (Sigma Chemical Co. A-6426) to the inoculum. The nitrogen disappearance of feedstuffs was determined at 0 and 2 hours in, approximately, $1.875 \mathrm{mg}$ of $\mathrm{N}$ incubated on each vessel. Data of degradation rates indicated that corn gluten feed, casein, dry grounded peanut grain, broiler litter using as adsorvent coffee rind, and cassava rasp showed the highest rates of protein degradation and the slowest degradation rates were obtained with corn meal, meat and bone meal, broiler litter using elephantgrass as adsorvent, sugar cane yeast and feather meal. The degradation parameters were alike as reported in situ. This approach offered a rapid and efficient evaluation of nitrogen degradation kinetic for concentrate feedstuffs. Nitrogen degradation rates of some grasses were underestimated.
\end{abstract}

Key Words: degradability, inhibitor in vitro, kinetic, nitrogen

\section{Introdução}

Os métodos in vitro para avaliar a degradação ruminal da proteína são de elevada potencialidade, devido à rápida predição dos padrões da fermentação e da degradação ruminal in vivo. Entretanto, a quantificação da taxa e a extensão da degradação, utilizando microrganismos ruminais, apresentam desvantagens, devido ao fato de os microrganismos utilizarem os produtos da degradação para crescimento, resultando em uma subestimativa da degradação. Warner (1956) verificou a existência de inibidores da

\footnotetext{
${ }^{1}$ Parte da Tese de Doutorado do primeiro autor, parcialmente financiada pela FAPEMIG.

${ }^{2}$ Aluno de Doutorado do DZO - UFV. E.mail: flondono@alunos.ufv.br

3 Professor do DZO - UFV 36571-000 Viçosa, MG. E.mail: scvfilho@mail.ufv.br

${ }^{4}$ Professor do DPI - UFV 36571-000 Viçosa, MG.

${ }^{5}$ Aluno de graduação UFV - Bolsista do CNPq.
} 
desaminação que seriam responsáveis pela baixa produção de amônia em alimentos concentrados avaliados in vitro. Broderick (1982) e Miller (1982) relataram recuperação incompleta dos produtos da degradação. Borchers (1967) adicionou tolueno, inibidor da desaminação dos aminoácidos, em estudos in vitro, para que os microrganismos ruminais não utilizassem os produtos da degradação, e quantificou a degradação protéica pela liberação de aminoácidos. Avaliando a degradação da proteína como resultado da recuperação de amônia e aminoácidos, Broderick (1987) demostrou que a incorporação de inibidores do metabolismo protéico (hidrazina e cloranfenicol), por intermédio do método dos inibidores in vitro, aumentou a recuperação dos produtos da degradação, permitindo, assim, inibição do uso dos produtos da degradação para crescimento microbiano.

De acordo com Broderick \& Clayton (1992), o uso do método de inibidores com tempo de incubação de 2 horas, utilizando-se a equação desenvolvida por Michaelis-Menten, resultou em excelentes estimativas das taxas de degradação. Entretanto, o método precisa de inúmeras análises de amônia e aminoácidos, o que pode limitar sua utilização na prática. Já Neutze et al. (1993), utilizando o mesmo método, avaliaram a degradação protéica como a liberação de nitrogênio solúvel em ácido tricloroacético, tendo como vantagem a determinação pelo método Kjeldahl. O procedimento de precipitação em ácido tricloroacético mede peptídeos em maior extensão que $\mathrm{N}$-amino. Existem evidências que mostram peptídeos em elevadas concentrações no líquido ruminal in vivo (Chen et al., 1987) e in vitro (Broderick \& Craig, 1983; Russell et al., 1983). Russell et al. (1983) encontraram concentrações elevadas de peptídeos após 7 horas de incubação, enquanto Broderick \& Wallace (1988) reportaram, em proteínas de rápida degradação como a caseína, aumentos da concentração de peptídeos em até 3 horas.

O objetivo deste trabalho foi estimar os parâmetros cinéticos da degradação da proteína em vários alimentos produzidos no Brasil, por meio da técnica dos inibidores in vitro, utilizando o sistema Kjeldahl.

\section{Material e Métodos}

A dinâmica da degradação dos compostos nitrogenados foi avaliada pela incubação in vitro com o uso de inibidores. O método descrito por Broderick (1987) foi modificado, utilizando a deter- minação dos compostos nitrogenados recuperados, por intermédio do método Kjeldahl, em vez de análises específicas de amônia e aminoácidos totais. Foi utilizado, como inóculo, líquido ruminal oriundo de bovino recebendo dieta com $60 \%$ de volumoso (capim-elefante) e $40 \%$ de concentrado (farelo de soja $60 \%$, fubá de milho $20 \%$, farelo de trigo $15 \%$, farinha de sangue $2 \%$, fosfato bicálcico $1 \%$, calcário $1 \%$ e sal mineral 1\%). Após a retirada do líquido, este foi filtrado inicialmente em camada dupla de gase e, no laboratório, em camada quádrupla. Na elaboração de $1000 \mathrm{~mL}$ (100 tubos) do meio fermentador, utilizaram-se $800 \mathrm{~mL}$ do inóculo, $2 \mathrm{~g}$ de bicarbonato de sódio em $50 \mathrm{~mL}$ de água destilada, $3,2 \mathrm{~g}$ de pectina em $100 \mathrm{~mL}$ de solução McDougall, 0,195 g de sulfato de hidrazina em $25 \mathrm{~mL}$ de solução McDougall e 0,045 g de cloranfenicol em 25 mL de solução McDougall, infundiu-se, constantemente, $\mathrm{CO}_{2}$ no meio. A solução McDougall com pectina foi preparada um dia antes da incubação, sendo infundido $\mathrm{CO}_{2}$ e mantida na sala de incubação $\left(39^{\circ} \mathrm{C}\right)$, durante a noite, semelhantemente a uma solução de McDougall de $500 \mathrm{~mL}$, sem $\mathrm{CO}_{2}$, utilizada para umedecer as amostras dos alimentos no dia da incubação.

Ao meio fermentador foram adicionados $3,2 \mathrm{~g}$ de amido, 3,2 $\mathrm{g}$ de xilose e $0,16 \mathrm{~mL}$ de antiespumante (Antifoam 204, Sigma Chemical Co. A-6426) e, posteriormente, procedeu-se à pré-incubação do fermentador por três horas (sempre foi preparado $20 \%$ a mais de todas as soluções e reagentes). A cada hora foram feitas medições do $\mathrm{pH}$ e análises de $\mathrm{NH}_{3}$. $\mathrm{O} \mathrm{pH}$ foi controlado com uma solução $3 \mathrm{~N}$ de $\mathrm{NaOH}$.

Durante a pré-incubação, as amostras dos alimentos foram colocadas em tubos de incubação de $50 \mathrm{~mL}$ e umedecidas ( $5 \mathrm{~mL}$ ) com solução McDougall, submetidas ao agitador (150 rpm) durante 35 minutos. Após a pré-incubação, adicionou-se primeiramente ao meio fermentador $0,234 \mathrm{~mL}$ de mercaptoethanol, em seguida, $25 \mathrm{~mL}$ da solução contendo sulfato de hidrazina e, após, $25 \mathrm{~mL}$ da solução contendo cloranfenicol, agitando-se lentamente. Posteriormente, foram adicionados $10 \mathrm{~mL}$ do meio fermentador aos tubos previamente umedecidos contendo amostra e $5 \mathrm{~mL}$ da solução de McDougall e procedeu-se à incubação.

Cada alimento foi incubado nos tempos 0 e 2 horas, na quantidade de $1,875 \mathrm{mg}$ de $\mathrm{N}$ para cada tubo de incubação. Nos tubos correspondentes ao tempo zero hora, foram colocados $1,25 \mathrm{~mL}$ de ácido tricloroacético (TCA) $65 \%$, os quais foram, posteriormente, guardados na geladeira. Os tubos de 2 horas 
foram mantidos na sala de incubação sob um agitador de mesa a $150 \mathrm{rpm}$. Após o período de incubação, foi colocado TCA na mesma proporção que para os tubos de zero hora, sendo também colocados na geladeira. Posteriormente, todos os tubos ( 0 e $2 \mathrm{~h}$ ) foram centrifugados a $15.300 \mathrm{~g}$ e $4^{\circ} \mathrm{C}$, durante 15 minutos, sendo o sobrenadante guardado a $4^{\circ} \mathrm{C}$ até a realização das análises correspondentes.

Foi utilizado o método Kjeldahl (AOAC, 1990) para determinar o teor de nitrogênio dos seguintes alimentos: caseína, farelos de soja e algodão contendo $30 \%$ de casca, glúten de milho, farelo de glúten de milho, farinhas de peixe, carne e ossos, sangue, penas, vísceras de aves e mista de vísceras de aves e suínos, levedura de cana-deaçúcar, fubá de milho, milho desintegrado com palha e sabugo (MDPS), quirera de milho, grão de milheto moído, grão de sorgo moído, grão de amendoim moído, raspa de mandioca, polpa cítrica, farelo de trigo e as camas de frango contendo como material absorvente casca de café, capimelefante e cepilha de madeira.

Avaliaram-se os seguintes volumosos: capimbraquiária (Brachiaria decumbens cv. Basiliski) ( $2^{\circ}$ ano), coletado no início das águas, com 45 dias de idade; capim-braquiarão (Brachiaria brizantha (Hochst) Stapf), coletado no início da seca; capimbraquiária do brejo (Brachiaria radicans Napper), capim-elefante (Pennisetum purpureum cv. Napier) e capim-tobiatã (Panicum maximum), coletados no início das águas com 30 dias de rebrota; capimandropogon (Andropogon gayanus Kunth); capimgordura (Melinis minutiflora Beauv); silagens de milho (Zea mays) e sorgo (Sorghum bicolor L. Moench), com ou sem inoculante microbiano; feno de capimtifton (Cynodon dactylon) com cinco semanas de idade e feno de capim-coastcross (Cynodon dactylon
L. Pers) e o estilosantes (Stylosanthes guianensis (Aubl.) $\mathrm{Sw}$ ) (cultivar mineirão coletado no início das águas).

Foram feitas determinações de matéria seca(MS), matéria orgânica (MO), matéria mineral (MM) e extrato etéreo (EE), seguindo os procedimentos descritos pelo AOAC (1990), além dos carboidratos totais (CHT), estimados pela equação (Sniffen et al., 1992): CHT $(\mathrm{MS})=100-(\% \mathrm{~PB}+\% \mathrm{EE}+\% \mathrm{MM}) . \mathrm{A}$ composição bromatológica dos alimentos concentrados e volumosos avaliados encontra-se, respectivamente, nas Tabelas 1 e 2 .

Os capins-tobiatã e andropogon aparecem com sigla ND, ou seja, não determinado, devido à falta de material.

As amostras foram moídas em moinho de bola e incubadas em duplicata em três dias diferentes, utilizando a caseína como alimento padrão. Os cálculos da degradação foram realizados de acordo com as seguintes equações:

Taxa de degradação, Kd $(/ \mathrm{h})=-\left(\operatorname{LnFID}_{2 \mathrm{~h}}\right.$ $\left.\mathrm{LnFID}_{\text {oh }}\right) / 2$

em que: LnFID $_{\text {oh }}=\left\{1-\left[\left(\left(\right.\right.\right.\right.$ Ninsolúvel $\left.\mathrm{TCA}_{\mathrm{oh}}\right) /$ Nincubado $)]\} ; \operatorname{LnFID}_{2 \mathrm{~h}}=\left\{1-\left[\left(\left(\right.\right.\right.\right.$ Ninsolúvel TCA $\left._{2 \mathrm{~h}}\right) /$ Nincubado)] \}, em que: Ninsolúvel em TCA, para 0 e $2 \mathrm{~h}=\mathrm{mg}$ (Ninsolúvel TCA - Nbranco); Fração B, B $(\%)=\left[\operatorname{Exp}\left(\operatorname{LnFID}_{0 \mathrm{~h}}\right) \times 100\right]$ e a proteína de escape calculada como: $\mathrm{Pe}(\%)=\mathrm{B}[\mathrm{Kp} /(\mathrm{Kd}+\mathrm{Kp})]$ assumindo-se uma taxa de passagem de $0,05 / \mathrm{h}$.

em que Pe corresponde à proteína de escape ou proteína não degradada no rúmen; $\mathrm{B}$, fração potencialmente degradável presente no tempo zero; $\mathrm{Kd}$, taxa de degradação; e Kp, taxa de passagem e TCA - Ácido tricloroacético

Os dados estimados sobre as taxas de degradação, frações B e proteína de escape, nas diferentes incubações, foram avaliados utilizando-se a estatística descritiva. 
Tabela 1 - Composição química dos alimentos avaliados (\% MS)

Table 1 - Chemical composition (\% DM) of the evaluated feedstuffs (\% DM)

\begin{tabular}{|c|c|c|c|c|c|c|}
\hline $\begin{array}{l}\text { Alimentos } \\
\text { Feedstuffs }\end{array}$ & $\begin{array}{c}\mathrm{MS}(\%) \\
D M\end{array}$ & $\begin{array}{l}\mathrm{MM} \\
\text { Ash }\end{array}$ & $\begin{array}{l}\mathrm{MO} \\
\mathrm{OM}\end{array}$ & $\begin{array}{l}\mathrm{PB} \\
C P\end{array}$ & $\begin{array}{l}\mathrm{EE} \\
E E\end{array}$ & $\begin{array}{l}\mathrm{CHT} \\
\mathrm{TCH}\end{array}$ \\
\hline Caseína & 89,19 & 2,06 & 97,94 & 97,95 & 0,00 & 0,00 \\
\hline $\begin{array}{l}\text { Casein } \\
\text { Farelo de soja }\end{array}$ & 87,77 & 8,56 & 91,44 & 46,81 & 1,62 & 43,01 \\
\hline $\begin{array}{l}\text { Soybean meal } \\
\text { Farelo de algodão } 30 \% \text { de casca } \\
\text { Cottonseed meal } 30 \% \text { rind }\end{array}$ & 89,43 & 4,69 & 95,31 & 25,06 & 1,22 & 69,03 \\
\hline $\begin{array}{l}\text { Glúten de milho } \\
\text { Corn gluten meal }\end{array}$ & 89,63 & 5,49 & 94,51 & 61,31 & 0,19 & 33,01 \\
\hline $\begin{array}{l}\text { Farelo de glúten de milho } \\
\text { Corn gluten feed }\end{array}$ & 87,74 & 10,33 & 89,67 & 18,31 & 4,17 & 67,19 \\
\hline $\begin{array}{l}\text { Farinha de peixe } \\
\text { Fish meal }\end{array}$ & 92,00 & 32,05 & 67,95 & 57,13 & 9,87 & 0,95 \\
\hline $\begin{array}{l}\text { Farinha de sangue } \\
\text { Blood meal }\end{array}$ & 91,00 & 2,98 & 97,02 & 81,00 & 0,15 & 15,87 \\
\hline $\begin{array}{l}\text { Farinha de carne e ossos } \\
\text { Meat and bone meal }\end{array}$ & 94,00 & 43,05 & 56,95 & 37,81 & 8,75 & 10,39 \\
\hline $\begin{array}{l}\text { Farinha de penas } \\
\text { Feather meal }\end{array}$ & 95,00 & 2,53 & 97,47 & 77,00 & 3,31 & 17,16 \\
\hline $\begin{array}{l}\text { Farinha de vísceras de aves } \\
\text { Fowl viscera meal }\end{array}$ & 93,46 & 17,60 & 82,4 & 54,13 & 11,59 & 16,68 \\
\hline $\begin{array}{l}\text { Farinha mista aves-suínos } \\
\text { Fowl-poultry viscera moisture meal }\end{array}$ & 94,30 & 16,50 & 83,95 & 49,94 & 9,66 & 23,90 \\
\hline $\begin{array}{l}\text { Levedura de cana-de-açúcar } \\
\text { Sugar cane yeast }\end{array}$ & 90,00 & 5,79 & 94,21 & 34,19 & 4,03 & 55,99 \\
\hline $\begin{array}{l}\text { Fubá de milho } \\
\text { Corn meal }\end{array}$ & 89,02 & 1,02 & 98,98 & 9,19 & 2,76 & 88,03 \\
\hline $\begin{array}{l}\text { MDPS } \\
\text { Corn, ears and cob }\end{array}$ & 87,00 & 1,55 & 98,45 & 7,90 & 2,15 & 88,30 \\
\hline $\begin{array}{l}\text { Quirera de milho } \\
\text { Grounded corn grain }\end{array}$ & 87,61 & 1,60 & 98,40 & 9,81 & 3,96 & 85,63 \\
\hline $\begin{array}{l}\text { Grão de milheto moído } \\
\text { Millet grain, dry ground }\end{array}$ & 88,18 & 6,00 & 94,00 & 15,94 & 5,36 & 72,70 \\
\hline $\begin{array}{l}\text { Grão de sorgo moído } \\
\text { Sorghum grain, dry ground }\end{array}$ & 87,17 & 1,89 & 98,11 & 9,44 & 3,09 & 85,08 \\
\hline $\begin{array}{l}\text { Grão de amendoim moído } \\
\text { Peanut grain, dry ground }\end{array}$ & 91,90 & 9,48 & 90,52 & 15,94 & 2,20 & 72,38 \\
\hline $\begin{array}{l}\text { Raspa de mandioca } \\
\text { Cassava rasp }\end{array}$ & 87,94 & 3,65 & 96,35 & 2,56 & 0,42 & 93,37 \\
\hline $\begin{array}{l}\text { Polpa cítrica } \\
\text { Citrus pulp }\end{array}$ & 85,50 & 7,18 & 92,82 & 6,48 & 2,34 & 84,00 \\
\hline $\begin{array}{l}\text { Farelo de trigo } \\
\text { Wheat bran }\end{array}$ & 83,10 & 5,47 & 94,53 & 14,25 & 3,53 & 77,75 \\
\hline $\begin{array}{l}\text { Cama de frango de casca de café } \\
\text { Broiler litter using coffee rind as adsorvent }\end{array}$ & 88,35 & 12,93 & 87,07 & 15,13 & 1,85 & 70,09 \\
\hline $\begin{array}{l}\text { Cama de frango de capim-elefante } \\
\text { Broiler litter using elephantgrass as adsorvent }\end{array}$ & 85,29 & 15,04 & 84,96 & 14,50 & 1,29 & 79,17 \\
\hline $\begin{array}{l}\text { Cama de frango de cepilha de madeira } \\
\text { Broiler litter using wood rind as adsorvent }\end{array}$ & 84,65 & 12,05 & 87,95 & 15,31 & 0,83 & 72,21 \\
\hline
\end{tabular}

MS - Matéria seca, MM - Matéria mineral, MO - Matéria orgânica, PB - Proteína bruta, EE - Extrato etéreo, CHT - Carboidratos totais. $D M$ - Dry matter, MM - Ash, OM - Organic matter, CP - Crude protein, EE - Ether extract, TCH - Total carbohydrates. 
Tabela 2 - Composição química dos volumosos avaliados (\% MS)

Table 2 - Chemical composition (\% DM) of the evaluated roughages (\% DM)

\begin{tabular}{|c|c|c|c|c|c|c|}
\hline $\begin{array}{l}\text { Alimentos } \\
\text { Feedstuffs }\end{array}$ & $\begin{array}{c}\mathrm{MS}(\%) \\
D M\end{array}$ & $\begin{array}{l}\mathrm{MM} \\
\text { Ash }\end{array}$ & $\begin{array}{l}\mathrm{MO} \\
\mathrm{OM}\end{array}$ & $\begin{array}{l}\mathrm{PB} \\
C P\end{array}$ & $\begin{array}{l}\mathrm{EE} \\
E E\end{array}$ & $\begin{array}{l}\mathrm{CHT} \\
\mathrm{TCH}\end{array}$ \\
\hline $\begin{array}{l}\text { Capim-braquiária } \\
\text { Signalgrass }\end{array}$ & 30,40 & 4,87 & 95,13 & 6,55 & 1,34 & 84,24 \\
\hline $\begin{array}{l}\text { Capim-braquiarão } \\
\text { Palisadegrass }\end{array}$ & 41,95 & 6,74 & 93,26 & 6,01 & 0,76 & 86,69 \\
\hline $\begin{array}{l}\text { Capim-braquiária do brejo } \\
\text { Tannergrass }\end{array}$ & 26,35 & 3,50 & 96,50 & 7,35 & 0,65 & 88,20 \\
\hline $\begin{array}{l}\text { Capim-elefante } \\
\text { Elephantgrass }\end{array}$ & 22,09 & 10,14 & 89,86 & 5,52 & 1,23 & 83,11 \\
\hline $\begin{array}{l}\text { Capim-tobiatã } \\
\text { Tobiatagrass }\end{array}$ & 48,18 & ND & $\mathrm{ND}$ & 3,29 & ND & $\mathrm{ND}$ \\
\hline $\begin{array}{l}\text { Capim-andropogon } \\
\text { Gambagrass }\end{array}$ & 28,68 & ND & ND & 7,12 & ND & ND \\
\hline $\begin{array}{l}\text { Capim-gordura } \\
\text { Honeygrass }\end{array}$ & 27,72 & 3,80 & 96,20 & 7,15 & 1,09 & 88,16 \\
\hline $\begin{array}{l}\text { Silagem de milho } \\
\text { Corn silage }\end{array}$ & 29,64 & 4,50 & 95,50 & 7,64 & 3,79 & 82,67 \\
\hline $\begin{array}{l}\text { Silagem de milho inoculada } \\
\text { Inoculated corn silage }\end{array}$ & 28,89 & 4,01 & 95,99 & 8,61 & 3,49 & 83,69 \\
\hline $\begin{array}{l}\text { Silagem de sorgo } \\
\text { Sorghum silage }\end{array}$ & 26,35 & 4,73 & 95,27 & 6,25 & 2,19 & 86,83 \\
\hline $\begin{array}{l}\text { Silagem de sorgo inoculada } \\
\text { Inoculated sorghum silage }\end{array}$ & 23,98 & 5,54 & 94,46 & 5,82 & 2,16 & 86,28 \\
\hline $\begin{array}{l}\text { Feno de capim-tifton } \\
\text { Tifton } 85 \text { bermudagrass hay }\end{array}$ & 88,19 & 4,65 & 95,35 & 19,06 & 1,35 & 74,94 \\
\hline $\begin{array}{l}\text { Feno de capim-coastcross } \\
\text { Coastcross hay }\end{array}$ & 88,88 & 5,03 & 94,97 & 7,55 & 1,34 & 86,08 \\
\hline $\begin{array}{l}\text { Estilosantes guianensis } \\
\text { Stylo }\end{array}$ & 31,00 & 5,78 & 94,22 & 14,83 & 2,89 & 74,50 \\
\hline
\end{tabular}

MS - Matéria seca, MM - Matéria mineral, MO - Matéria orgânica, PB - Proteína bruta, EE - Extrato etéreo, CHT - Carboidratos totais. $D M$ - Dry matter, MM - Ash, OM - Organic matter, CP - Crude protein, EE - Ether extract, TCH - Total carbohydrates. $\mathrm{ND}=$ não-determinado $(N D=$ not determined $)$.

\section{Resultados e Discussão}

A principal alteração do método dos inibidores in vitro (IIV) foi a determinação dos compostos nitrogenados, por intermédio do sistema Kjeldahl, quantificando o N-total, em vez da soma do $\mathrm{N}$-aminoácido e $\mathrm{N}-\mathrm{NH}_{3}$. Por outro lado, por intermédio do sistema Kjeldahl, é possível também determinar a fração correspondente ao $\mathrm{N}-\mathrm{NH}_{3} \mathrm{e}$, por diferença do $\mathrm{N}-$ Total e $\mathrm{N}-\mathrm{NH}_{3}$, o nitrogênio aminoácido (N-AA), porém esta diferença não foi calculada neste trabalho.

Os valores médios estimados dos parâmetros da degradação da proteína dos alimentos concentrados estão apresentados na Tabela 3. As estimativas referentes às taxas de degradação mostraram que os alimentos concentrados: farelo de glúten de milho, caseína, grão de amendoim moído, cama de frango contendo casca de café como material absorvente e raspa de mandioca possuem proteínas de rápida degradação. Observaram-se também lentas taxas de degradação para o fubá de milho, farinha de carne e ossos, cama de frango contendo capim-elefante como material absorvente, levedura de cana-de-açúcar e farinha de penas.

Como era de se esperar, a maior taxa de degradação resultou em menos proteína disponível para a digestão intestinal. Os valores médios estimados da proteína de escape dos alimentos que apresentaram elevadas taxas de degradação variaram de 2,0\%, para farelo de glúten de milho, a 15,05\%, para caseína.

Do ponto de vista prático, mais proteína pode ser degradada que sintetizada e haverá, por conseguinte, perdas de N-protéico no rúmen na forma de amônia $\left(\mathrm{NH}_{3}\right)$, quando for oferecida aos ruminantes proteína de rápida degradação, de tal forma que os microrganismos não podem utilizar todos os aminoácidos e $\mathrm{NH}_{3}$ liberados. A caseína tem sido utilizada como alimento padrão nos estudos in vitro, por apresentar 
Tabela 3 - Médias e desvio-padrão (DP) para as taxas de degradação $(\mathrm{Kd})$, fração $\mathrm{B}$ e proteína que escapa à degradação ruminal, obtidas para alimentos concentrados, utilizando o método de inibidores in vitro

Table 3 - Means and standard deviations for degradation rates, fraction B and estimated ruminal protein escape of concentrate feedstuffs, using an inhibitor in vitro method

\begin{tabular}{|c|c|c|c|c|c|c|}
\hline \multirow[t]{2}{*}{$\begin{array}{l}\text { Alimentos } \\
\text { Feedstuffs }\end{array}$} & \multicolumn{2}{|c|}{$\begin{array}{l}\mathrm{Kd}(/ \mathrm{h}) \\
\quad K d\end{array}$} & \multicolumn{2}{|c|}{$\begin{array}{l}\text { Fração B }(\%) \\
\text { Fraction B }\end{array}$} & \multicolumn{2}{|c|}{$\begin{array}{l}\text { Proteína de escape (\%) } \\
\text { Estimated protein escape }\end{array}$} \\
\hline & $\begin{array}{l}\text { Média }^{1} \\
\text { Means }\end{array}$ & $\begin{array}{l}\mathrm{DP} \\
S D\end{array}$ & $\begin{array}{l}\text { Média }^{1} \\
\text { Means }\end{array}$ & $\begin{array}{l}\mathrm{DP} \\
S D\end{array}$ & $\begin{array}{c}\text { Média } \\
\text { Means }\end{array}$ & $\begin{array}{l}\text { DP } \\
S D\end{array}$ \\
\hline $\begin{array}{l}\text { Caseína } \\
\text { Casein }\end{array}$ & 0,261 & 0,008 & 93,920 & 1,670 & 15,050 & 0,410 \\
\hline $\begin{array}{l}\text { Farelo de soja } \\
\text { Soybean meal }\end{array}$ & 0,154 & 0,002 & 84,130 & 0,360 & 20,830 & 0,410 \\
\hline $\begin{array}{l}\text { Farelo de algodão } 30 \% \text { casca } \\
\text { Cottonseed meal } 30 \% \text { rind }\end{array}$ & 0,063 & 0,002 & 75,650 & 0,230 & 33,500 & 0,550 \\
\hline $\begin{array}{l}\text { Glúten de milho } \\
\text { Corn gluten meal }\end{array}$ & 0,042 & 0,003 & 86,320 & 2,930 & 46,830 & 3,370 \\
\hline $\begin{array}{l}\text { Farelo de glúten de milho } \\
\text { Corn gluten feed }\end{array}$ & 0,527 & 0,002 & 22,180 & 0,090 & 2,000 & 0,010 \\
\hline $\begin{array}{l}\text { Farinha de peixe } \\
\text { Fish meal }\end{array}$ & 0,043 & 0,002 & 83,620 & 0,200 & 45,000 & 0,890 \\
\hline $\begin{array}{l}\text { Farinha de sangue } \\
\text { Blood meal }\end{array}$ & 0,042 & 0,002 & 79,080 & 2,520 & 42,660 & 1,970 \\
\hline $\begin{array}{l}\text { Farinha de carne e ossos } \\
\text { Meat and bone meal }\end{array}$ & 0,035 & 0,001 & 85,630 & 0,170 & 50,000 & 0,630 \\
\hline $\begin{array}{l}\text { Farinha de penas } \\
\text { Feather meal }\end{array}$ & 0,039 & 0,002 & 30,450 & 0,260 & 17,330 & 0,520 \\
\hline $\begin{array}{l}\text { Farinha de vísceras de aves } \\
\text { Fowl viscera meal }\end{array}$ & 0,073 & 0,007 & 52,150 & 0,420 & 23,160 & 0,550 \\
\hline $\begin{array}{l}\text { Farinha mista aves-suínos } \\
\text { Fowl-poultry viscera moisture meal }\end{array}$ & 0,075 & 0,003 & 36,930 & 0,210 & 14,830 & 0,410 \\
\hline $\begin{array}{l}\text { Levedura de cana-de-açúcar } \\
\text { Sugar cane yeast }\end{array}$ & 0,037 & 0,001 & 92,520 & 0,340 & 53,000 & 0,860 \\
\hline $\begin{array}{l}\text { Fubá de milho } \\
\text { Corn meal }\end{array}$ & 0,022 & 0,000 & 84,570 & 0,300 & 52,000 & 0,630 \\
\hline $\begin{array}{l}\text { MDPS } \\
\text { Corn, ears and cob }\end{array}$ & 0,181 & 0,004 & 71,730 & 0,680 & 15,330 & 0,520 \\
\hline $\begin{array}{l}\text { Quirera de milho } \\
\text { Grounded corn grain }\end{array}$ & 0,067 & 0,003 & 78,350 & 1,790 & 33,500 & 1,050 \\
\hline $\begin{array}{l}\text { Grão de milheto moído } \\
\text { Millet grain, dry ground }\end{array}$ & 0,041 & 0,001 & 95,860 & 0,270 & 52,330 & 0,820 \\
\hline $\begin{array}{l}\text { Grão de sorgo moído } \\
\text { Sorghum grain, dry ground }\end{array}$ & 0,043 & 0,002 & 85,920 & 0,750 & 46,500 & 0,840 \\
\hline $\begin{array}{l}\text { Grão de amendoim moído } \\
\text { Peanut grain, dry ground }\end{array}$ & 0,244 & 0,005 & 67,900 & 0,740 & 11,500 & 0,550 \\
\hline $\begin{array}{l}\text { Raspa de mandioca } \\
\text { Cassava rasp }\end{array}$ & 0,269 & 0,013 & 63,550 & 2,110 & 9,830 & 0,410 \\
\hline $\begin{array}{l}\text { Polpa cítrica } \\
\text { Citrus dry pulp }\end{array}$ & 0,049 & 0,001 & 41,630 & 0,210 & 21,170 & 0,410 \\
\hline $\begin{array}{l}\text { Farelo de trigo } \\
\text { Wheat bran }\end{array}$ & 0,111 & 0,003 & 74,750 & 0,230 & 23,000 & 0,630 \\
\hline $\begin{array}{l}\text { Cama de frango de casca de café } \\
\text { Broiler litter using coffee rind as adsorvent }\end{array}$ & 0,269 & 0,018 & 36,950 & 1,100 & 5,670 & 0,520 \\
\hline $\begin{array}{l}\text { Cama de frango de capim-elefante } \\
\text { Broiler litter using elephantgrass as adsorvent }\end{array}$ & 0,033 & 0,002 & 39,680 & 0,820 & 23,670 & 0,520 \\
\hline $\begin{array}{l}\text { Cama de frango de cepilha de madeira } \\
\text { Broiler litter using wood rind as adsorvent }\end{array}$ & 0,061 & 0,006 & 45,170 & 0,410 & 20,500 & 1,050 \\
\hline
\end{tabular}

1 Dados de 18 observações para caseína e seis observações para os demais alimentos.

1 Data of 18 observations for casein and six observations for the other feedstuffs. 
excelente composição aminoacídica e ser praticamente toda degradada no rúmen, ou seja, ter rápida degradação. No presente trabalho também foi utilizada como padrão durante todas as avaliações.

A estimativa média das taxas de degradação (Kd) da caseína foi de 0,261/h. Comparando-se os valores obtidos com os da literatura, nota-se que os resultados de $\mathrm{Kd}$ e fração $\mathrm{B}$ foram semelhantes àqueles reportados por Broderick $(1978,1987,1995)$ e Craig et al. (1984), utilizando o mesmo método e avaliando o desaparecimento através da recuperação de $\mathrm{N}-\mathrm{NH}_{3}$ e N-aminoácido. A proteína de escape foi semelhante àquela obtida em estudos com animais fistulados no abomaso por McDonald \& Hall (1954), $13 \%$, para uma taxa de passagem de $0,06 / \mathrm{h}$.

O farelo de soja é considerado de degradabilidade intermediária e as estimativas médias para a taxa de degradação foram semelhantes àquelas reportadas por Broderick (1987) de $0,159 / \mathrm{h}$, utilizando uma relação 60:40 para volumoso:concentrado na alimentação dos bovinos doadores de líquido ruminal, e próximas às encontradas por England et al. (1997), de 0,158/h; Broderick (1995), de 0,166/h; Broderick \& Clayton (1992) de 0,140/h; e Broderick \& Wallace (1988) de $0,166 / \mathrm{h}$. Avaliando a degradabilidade por intermédio do método de inibidores e utilizando uma relação 50:50 para volumoso:concentrado na alimentação dos bovinos, Neutze et al. (1993) reportaram Kd de 0,069/h e 0,092/h para farelo de soja, quando a relação foi 80:20. Por outro lado, as estimativas da fração B foram 7,8\% menores que as reportadas por esses autores e a proteína de escape, semelhante à obtida por Broderick \& Clayton (1992), de $24 \%$. Já o NRC (1989) adotou valores de $35 \%$ para a proteína de escape do farelo de soja. Uma explicação para a similaridade das estimativas encontradas na presente pesquisa com aquelas obtidas por outros autores é que o meio nutritivo utilizado foi eficaz na manutenção dos valores de $\mathrm{pH}$ entre 6,7-7,0 para todos os alimentos avaliados. Valores inferiores a 6,2 no $\mathrm{pH}$ afetam o crescimento dos microrganismos ruminais especialmente os fibrolíticos (Mertens \& Loften, 1980). Nota-se, portanto, que o sistema foi estável, como pode ser observado pelos baixos valores do desvio-padrão para as estimativas obtidas.

As estimativas médias para $\mathrm{Kd}$ do farelo de algodão foram próximas às encontradas por Neutze et al. (1993), utilizando uma dieta com relação 50:50 volumoso:concentrado para os bovinos doadores. A proteína da farinha de peixe é considerada resistente à degradação ruminal. Os resultados para $\mathrm{Kd}, \mathrm{B}$ e para proteína de escape foram semelhantes aos encontrados por Broderick \& Wallace (1988) e Hristov \& Broderick (1994), avaliando farinha de peixe de alta solubilidade. O NRC (1989) considerou um valor de $60 \%$ para a proteína de escape da farinha de peixe e $49 \%$ para a farinha de carne e ossos. Os resultados da taxa de degradação da fração $B$ e proteína de escape da farinha de carne e ossos foram semelhantes aos obtidos por Broderick (1987) e NRC (1989) para a proteína de escape $(49 \%)$.

Avaliando dois tipos de farinha de sangue, England et al. (1997) encontraram taxas de degradação muito mais lentas que as obtidas neste trabalho, $0,01 / \mathrm{h}$ e 0,04/h, respectivamente. Entretanto, os resultados para taxa de degradação da farinha de penas encontrados por esses autores foram próximos aos obtidos na presente pesquisa.

As farinhas de vísceras de aves e mista de vísceras de aves e suínos resultaram em taxas de degradação próximas $(0,073 / \mathrm{h}$ e $0,075 / \mathrm{h})$, já a fração B foi $29,18 \%$ maior na farinha de vísceras, quando comparada à mista de aves e suínos (52,15 e 36,93\%).

O fubá de milho, a quirera de milho e o MDPS apresentaram teores de proteína $(\mathrm{PB})$ próximos (Tabela 1). Por outro lado, as taxas de degradação e a proteína de escape desses três alimentos foram diferentes. A quirera e o fubá de milho apresentaram taxas de degradação lentas. Fica implícito que alimentos com teores de PB similares, mas com diferenças nas taxas de degradação e proteína de escape, podem resultar em predições incorretas sobre o desempenho animal, se na formulação das rações não forem consideradas a dinâmica ruminal e a proteína de escape. O MDPS apresentou taxa de degradação intermediária. O NRC (1989) adotou valores de 52\% para a proteína de escape do milho, valores semelhantes aos encontrados nesta pesquisa. Já para o glúten de milho, os dados estimados para $\mathrm{Kd}$ de 0,042/h foram próximos aos reportados por Hristov \& Broderick (1994), de 0,034/h.

Ao se analisarem as taxas de degradação dos grãos moídos, observou-se que as estimativas de $\mathrm{Kd}$ para sorgo e milheto foram semelhantes e o amendoim apresentou rápida taxa de degradação. As estimativas médias para a proteína de escape do sorgo grão moído foram semelhantes às reportadas pelo NRC (2001) de 49\%.

Os valores da taxa de degradação para levedura 
de cana-de-açúcar e polpa cítrica foram semelhantes, entretanto, vale ressaltar que a proteína de escape da levedura de cana de açúcar $(34,19 \%$ de PB) apresentou, juntamente com o fubá de milho e o grão de milheto moído, o maior valor numérico, 53, 52 e 52\%, respectivamente, quando comparada com os outros alimentos avaliados.

A cama de frango tem sido utilizada como fonte de compostos nitrogenados protéicos e não-protéicos, e seu perfil nutricional é definido pelo material absorvente utilizado. O teor de proteína bruta da cama de frango, utilizando como material absorvente casca de café, foi aproximadamente $4,16 \%$ maior que a contendo capim-elefante e semelhante àquela com cepilha de madeira. Neste caso, a taxa de degradação da cama de frango contendo casca de café foi 8,8 vezes maior $(0,269 / \mathrm{h})$ que a taxa de degradação da cama de frango à base de capim-elefante $(0,033 / \mathrm{h})$ e 4,4 vezes maior que a taxa de degradação da cama de frango à base de cepilha de madeira $(0,061 / \mathrm{h})$. Portanto, seu uso deve ser com uma fonte energética de rápida fermentação no rúmen para máxima eficiência microbiana. Avaliando a degradação ruminal da cama de frango utilizando como base capim-elefante por intermédio da técnica in situ, Oliveira (1998) encontrou taxa de degradação de $0,04 / \mathrm{h}$, próxima à encontrada no presente trabalho.

Consta da Figura 1 a cinética da degradação da caseína nas 18 diferentes avaliações realizadas. Observa-se que a regressão foi linear, apresentando coeficiente de regressão " $b$ " de -0,261 e coeficiente linear "a" próximo de zero, além de elevado coeficiente de determinação 0,99 . A equação $\operatorname{Ln}$ FID $=a+$ Kd.t, em que $\mathrm{Kd}=-\left(\mathrm{Ln}_{2}-\mathrm{Ln}_{0}\right) / 2$ mostra $\mathrm{Kd}=0,261$, o que significa que $26,1 \%$ do nitrogênio da caseína remanescente foi degradado por hora.

Normalmente, têm sido feitas comparações da cinética da degradação entre os métodos in situ e in vitro, em virtude de as estimativas pelo método in situ resultarem, às vezes, em valores de degradação mais próximos aos encontrados in vivo. Entretanto, vale ressaltar que os objetivos de cada técnica são diferentes (Mertens, 1993). Embora a comparação entre parâmetros cinéticos obtidos entre estas duas técnicas não seja aconselhada (Mertens, 1993), os valores das taxas de degradação para as incubações in vitro foram semelhantes aos estimados in situ para farelo de trigo, fubá de milho, cama de frango contendo cepilha de madeira como material absorvente, farinha de peixe, farelo de algodão e grão moído de sorgo,

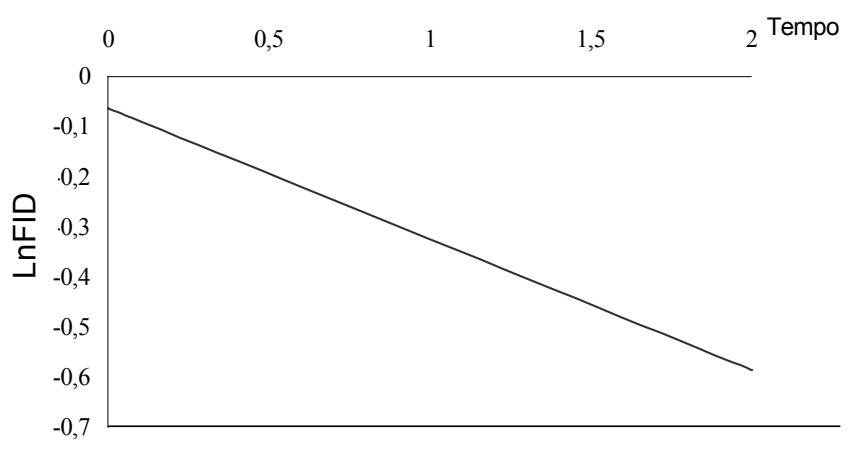

Figura 1 - Logaritmo natural da fração indegradável da caseína em função do tempo, utilizando o método dos inibidores in vitro.

Figure 1 - Natural logarithm of undegraded fraction of casein in function of time, using an inhibitor method.

conforme Valadares Filho et al. (1990), Valadares Filho et al. (1991) e Valadares Filho (1994), e para farelo de soja, segundo Londoño Hernández (1995); polpa cítrica (Goes et al., 2000a) e grão de sorgo moído (Martins et al., 1997). Vale lembrar que a comparação de alimentos pode ser feita sempre por técnicas in vitro e a comparação entre dietas, por técnicas in vivo (Malafaia, 1997).

As estimativas médias dos parâmetros cinéticos da degradação da proteína dos alimentos volumosos são apresentadas na Tabela 4. Observou-se que as estimativas médias das taxas de degradação do feno de capim-Tifton, capim-braquiarão e capimandropogon foram elevadas, indicando que esses alimentos possuem proteínas de rápida degradação. Entretanto, lentas taxas de degradação foram observadas para o capim-braquiária e as silagens de sorgo com ou sem inoculante.

As proteínas das forragens são extensamente degradadas no rúmen, sendo utilizadas para síntese protéica pelos microrganismos (Beever \& Siddons, 1986). De acordo com os resultados, não seriam esperadas elevadas proporções da proteína de escape.

De acordo com Broderick (1995), o método de inibidores in vitro possui certas desvantagens, entre elas está aquela relacionada com a proteína de lenta degradação apresentada com alguns volumosos. As taxas de degradação determinadas para alimentos contendo níveis elevados de amônia e aminoácidos livres são menos acuradas, em razão de a taxa de degradação ser estimada através do lento desaparecimento de $\mathrm{NH}_{3}$ e aminoácidos, resultando em acúmulo de amônia e deficiência de energia no meio 
Tabela 4 - Médias e desvio-padrão (DP) para as taxas de degradação (Kd), fração B e proteína que escapa à degradação ruminal obtidas para alimentos volumosos, utilizando o método de inibidores in vitro

Table 4 - Means and standard deviations for degradation rates, fraction B and estimated ruminal protein escape of forage feedstuffs, using an inhibitor in vitro method

\begin{tabular}{|c|c|c|c|c|c|c|}
\hline \multirow[t]{2}{*}{$\begin{array}{l}\text { Alimentos } \\
\text { Feedstuffs }\end{array}$} & \multicolumn{2}{|c|}{$\begin{array}{c}\mathrm{Kd}(/ \mathrm{h}) \\
\quad K d\end{array}$} & \multicolumn{2}{|c|}{$\begin{array}{c}\text { Fração B }(\%) \\
\text { Fraction B }\end{array}$} & \multicolumn{2}{|c|}{$\begin{array}{l}\text { Proteína de escape }(\%) \\
\text { Estimated protein escape }\end{array}$} \\
\hline & $\begin{array}{l}\text { Média }^{1} \\
\text { Means }\end{array}$ & $\begin{array}{l}\mathrm{DP} \\
S D\end{array}$ & $\begin{array}{l}\text { Média }{ }^{1} \\
\text { Means }\end{array}$ & $\begin{array}{l}\mathrm{DP} \\
S D\end{array}$ & $\begin{array}{c}\text { Média }^{1} \\
\text { Means }\end{array}$ & $\begin{array}{l}\mathrm{DP} \\
S D\end{array}$ \\
\hline $\begin{array}{l}\text { Capim-braquiária } \\
\text { Signalgrass }\end{array}$ & 0,005 & 0,0100 & 58,830 & 0,410 & 53,830 & 0,750 \\
\hline $\begin{array}{l}\text { Capim-braquiarão } \\
\text { Palisadegrass }\end{array}$ & 0,102 & 0,0030 & 79,880 & 0,290 & 26,500 & 0,550 \\
\hline $\begin{array}{l}\text { Capim-braquiária do brejo } \\
\text { Tannergrass }\end{array}$ & 0,021 & 0,0008 & 85,570 & 0,310 & 60,170 & 0,750 \\
\hline $\begin{array}{l}\text { Capim-elefante } \\
\text { Elephantgrass }\end{array}$ & 0,013 & 0,0007 & 97,900 & 0,290 & 78,160 & 0,840 \\
\hline $\begin{array}{l}\text { Capim-Tobiatã } \\
\text { Tobiatagrass }\end{array}$ & 0,018 & 0,0008 & 90,910 & 0,350 & 66,500 & 0,830 \\
\hline $\begin{array}{l}\text { Capim-Andropogon } \\
\text { Gambagrass }\end{array}$ & 0,080 & 0,0010 & 98,530 & 0,380 & 37,830 & 0,410 \\
\hline $\begin{array}{l}\text { Capim-gordura } \\
\text { Molassesgrass }\end{array}$ & 0,040 & 0,0008 & 95,970 & 0,510 & 53,000 & 0,630 \\
\hline $\begin{array}{l}\text { Silagem milho } \\
\text { Corn silage }\end{array}$ & 0,035 & 0,0040 & 63,150 & 0,340 & 37,000 & 1,670 \\
\hline $\begin{array}{l}\text { Silagem milho inoculado } \\
\text { Inoculated corn silage }\end{array}$ & 0,013 & 0,0008 & 41,700 & 0,320 & 33,000 & 0,630 \\
\hline $\begin{array}{l}\text { Silagem sorgo } \\
\text { Sorghum silage }\end{array}$ & 0,007 & 0,0004 & 72,280 & 0,430 & 62,670 & 0,520 \\
\hline $\begin{array}{l}\text { Silagem sorgo inoculado } \\
\text { Inoculated sorghum silage }\end{array}$ & 0,007 & 0,0006 & 74,250 & 0,260 & 65,000 & 0,630 \\
\hline $\begin{array}{l}\text { Feno capim-tifton } \\
\text { Tifton } 85 \text { bermudagrass hay }\end{array}$ & 0,148 & 0,0010 & 91,200 & 0,620 & 23,000 & 0,010 \\
\hline $\begin{array}{l}\text { Feno capim-coastcross } \\
\text { Coastcross hay }\end{array}$ & 0,029 & 0,0020 & 77,450 & 0,160 & 48,670 & 1,210 \\
\hline $\begin{array}{l}\text { Estilosanthes guianensis } \\
\text { Stylo }\end{array}$ & 0,062 & 0,0170 & 88,960 & 0,250 & 39,670 & 0,520 \\
\hline
\end{tabular}

${ }^{1}$ Média de seis observações.

${ }^{1}$ Mean of six observations.

fermentador, para suportar o crescimento microbiano e uso do excesso de proteína degradável.

As estimativas médias da taxa de degradação da silagem de sorgo foram semelhantes às reportadas por Martins et al. (1998), de $0,017 / \mathrm{h}$, e para silagem de milho foram próximas às reportadas por Valadares Filho et al. (1990), de $0,035 / \mathrm{h}$, e semelhantes às encontradas por Backes et al. (2000) e Goes et al. (2000b), respectivamente, $0,02 / \mathrm{h}$ e $0,04 / \mathrm{h}$, para silagem de milho com inoculante (Backes et al., 2000) de 0,016/h. Segundo Van Soest (1994), os aditivos têm duas principais vantagens na silagem: influenciar a fermentação, favorecendo a preservação, e alterar a composição, melhorando o valor nutritivo. No presente trabalho, não foi alterada a cinética ruminal da silagem de sorgo, devido à inoculação microbiana, já para a silagem de milho a inoculação diminuiu a taxa de degradação dos compostos nitrogenados. Keady et al. (1994), estudando o efeito do inoculante microbiano na degradabilidade da silagem, constataram que o tratamento com inoculante melhorou a digestibilidade das silagens e aumentou a degradabilidade ruminal dos compostos nitrogenados, aumentando o valor da fração solúvel. Morais (1995) não encontrou efeito da inoculação sobre a degradabilidade ruminal in situ da silagem de milho.

O feno de capim-coastcross apresentou $\mathrm{Kd}$ próxima às encontradas por Oliveira et al. (1999), Goes et al. (2000b), Ítavo et al. (2000) e Franzolin et al. (2000), respectivamente, $0,026 / \mathrm{h}, 0,034 / \mathrm{h}, 0,032 / \mathrm{h}$, e $0,023 / \mathrm{h}$. Estimativas semelhantes para taxa de degradação do estilosantes foram encontradas por Ladeira et al. (2000), de 0,096/h. 
Avaliando a degradabilidade ruminal in situ de vários volumosos, Martínez (1999) encontrou Kd de $0,069 / \mathrm{h}$ para capim-braquiarão e de $0,104 / \mathrm{h}$ para o capim-braquiária. No presente trabalho, as taxas de degradação foram de $0,005 / \mathrm{h}$ e $0,102 / \mathrm{h}$ para os capins-braquiária e braquiarão, respectivamente.

As estimativas médias da taxa de degradação para os capins-tobiatã e feno de capim-Tifton foram diferentes daquelas encontradas por Pinto et al. (1998) e Ítavo et al. (2000), respectivamente, 0,054/h e $0,035 /$ h. Já para o capim-elefante, o resultado foi próximo do relatado por Londoño Hernández (1995), de $0,018 / \mathrm{h}$, ao avaliar a degradabilidade ruminal do capim elefante seco a $55^{\circ} \mathrm{C}$.

\section{Conclusões}

O uso do método dos inibidores in vitro, utilizando o sistema Kjeldahl, permitiu uma avaliação rápida e eficiente da cinética de degradação da proteína bruta dos alimentos concentrados. As taxas de degradação de alguns alimentos volumosos foram subestimadas.

\section{Literatura Citada}

ASSOCIATION OF OFFICIAL ANALYTICAL CHEMISTS AOAC. Official methods of analysis. 15.ed Arlington: 1990. v.1. $117 \mathrm{p}$.

BACKES, A.A.; SANCHEZ, B.L.M.; GONÇALVES, F.M.B. et al. Avaliação da degradabilidade ruminal in situ da matéria seca e proteína bruta de vários alimentos. In: REUNIÃO ANUAL DA SOCIEDADE BRASILEIRA DE ZOOTECNIA, 37., 2000, Viçosa, MG. Anais... Viçosa: Sociedade Brasileira de Zootecnia, 2000. p.336.

BEEVER, D.E.; SIDDONS, R.C. Digestion and metabolism in the grazing ruminant. In: MILLIGAN, L.P.; GROVUM, W.L.; DOBSON, A. (Eds.) Control of digestion and metabolism in ruminants. Englewood Cliffs: PrenticeHall, 1986. p.479.

BORCHERS, R. Proteolytic activity of rumen fluid in vitro. Journal of Animal Science, v.24, n.6, p.1033-1038, 1967.

BRODERICK, G.A. Methodology for the determining ruminal degradability of feed proteins In: SIMPÓSIO INTERNACIONAL SOBRE EXIGÊNCIAS NUTRICIONAIS DE RUMINANTES, 1995, Viçosa, MG. Anais... Viçosa, MG: Universidade Federal de Viçosa, 1995. p.139-176.

BRODERICK, G.A.; CLAYTON, M.K. Ruminal protein degradation rates estimated by nonlinear regression analysis of Michaelis-Menten in vitro data. British Journal of Nutrition, v.67, n.1, p.27-42, 1992.

BRODERICK, G.A.; WALLACE, R.J. Effects of dietary nitrogen source on concentrations of ammonia, free amino acids and fluorescamine reactive peptides in the sheep rumen. Journal of Animal Science, v.66, n.8, p.2233-2238, 1988.

BRODERICK, G.A. Determination of protein degradation rates using a rumen in vitro system containing inhibitors of microbial nitrogen metabolism. British Journal of Nutrition, v.58, n.5, p.463-475, 1987.

BRODERICK, G.A.; CRAIG, W.M. Mechanism of protein degradation by rumen microbes. Federation Proceedings, v.42, n.3, p.532, 1983. (Abstr.)

BRODERICK, G.A. Estimation of protein degradation using in situ and in vitro methods. In: OWENS, F.N. (Ed.) Protein requirements for cattle: symposium. Stillwater: Oklahoma State University, 1982. p.72-80

BRODERICK, G.A. In vitro procedures for estimating rates of ruminal protein degradation and proportions of protein escaping the rumen undegraded. Journal of Nutrition, v.108, n.1, p.181-190, 1978.

CRAIG, W.M.; HONG, B.J.; BRODERICK, G.A. et al. In vitro inoculum enriched with particle-associated microorganisms for determining rates of fibre digestion and protein degradation. Journal of Dairy Science, v.67, n.12, p.2902-2909, 1984.

CHEN, G.; SNIFFEN, C.J.; RUSSELL, J.B. Concentration and estimated flow of peptides from the rumen of dairy cattle: effects of protein quantity, protein solubility, and feeding frequency. Journal of Dairy Science, v.70, n.4, p.983-992, 1987.

ENGLAND, M.L.; BRODERICK, G.A.; SHAVER, R.D. et al. Comparison of in situ and in vitro techniques for measuring ruminal degradation of animal by-product proteins. Journal of Dairy Science, v.80, n.11, p.2925-2931, 1997.

FRANZOLIN, T.M.H.; SILVEIRA, A.C.; FRANZOLIN, R. Degradabilidade in situ com sacos de náilon, de dois tamanhos de poros, em bubalinos e bovinos sob dietas com níveis crescentes de fibra em detergente neutro. In: REUNIÃO ANUAL DA SOCIEDADE BRASILEIRA DE ZOOTECNIA, 37., 2000, Viçosa, MG. Anais... Viçosa, MG: Sociedade Brasileira de Zootecnia, 2000. p.377.

GOES, B.T.H.R.; TEIXEIRA, J.C.; MANCIO, A.B. et al. Degradação ruminal da matéria seca e proteína bruta de alguns alimentos em novilhos da raça nelore. In: REUNIÃO ANUAL DA SOCIEDADE BRASILEIRA DE ZOOTECNIA, 37., 2000, Viçosa, MG. Anais... Viçosa: Sociedade Brasileira de Zootecnia, 2000a. p.379.

GOES, B.T.H.R.; TEIXEIRA, J.C.; MANCIO, A.B. et al. Digestão ruminal da matéria seca, proteína bruta e fibra em detergente neutro de diferentes volumosos em vacas nelore. In: REUNIÃO ANUAL DA SOCIEDADE BRASILEIRA DE ZOOTECNIA, 37., 2000, Viçosa, MG. Anais... Viçosa: Sociedade Brasileira de Zootecnia, 2000b. p.399.

HRISTOV, A., BRODERICK, G.A. In vitro determination of ruminal protein degradability using ${ }^{15} \mathrm{~N}$-ammonia to correct for microbial nitrogen uptake. Journal of Animal Science, v.72, n.7, p.1344-1353, 1994.

ÍTAVO, L.C.V.; SILVA, F.F.; CARDOSO, C.E. et al. Degradabilidade de fenos de gramíneas do gênero cynodon In: REUNIÃO ANUAL DA SOCIEDADE BRASILEIRA DE ZOOTECNIA, 37., 2000, Viçosa, MG. Anais... Viçosa: Sociedade Brasileira de Zootecnia, 2000. p.336

KEADY, T.W.; STEEN, R.W.; KILPATRICK, D.J. et al. Effects of inoculant treatment on silage fermentation, digestibility and intake by growing cattle. Grass and Forage Science, v.49, n.3, p.284-294, 1994.

LADEIRA, M.M.; RODRIGUEZ, M.N.; GONÇALVES, L.C. et al. Avaliação nutricional do feno de stylosantes guianensis: 3. Degradabilidade ruminal e taxa de passagem. In: REUNIÃO ANUAL DA SOCIEDADE BRASILEIRA DE ZOOTECNIA, 37., 2000, Viçosa, MG. Anais... Viçosa: Sociedade Brasileira de Zootecnia, 2000. p.349-350. 
LONDOÑO HERNÁNDEZ, F.I. Avaliação da técnica de saco de náilon móvel. Santa Maria, RS: Universidade Federal de Santa Maria, 1995. 127p. Dissertação (Mestrado em Zootecnia) - Universidade Federal de Santa Maria, 1995.

MALAFAIA, P.A.M. Taxas de digestão das frações protéicas e de carboidratos de alimentos por técnicas in situ, in vitro e de produção de gases. Viçosa, MG: Universidade Federal de Viçosa, 1997. 85p. Tese (Doutorado em Zootecnia) Universidade Federal de Viçosa, 1997.

MARTINS, S.A.; ZEOULA, L.M.; PRADO, I.N. et al. Degradabilidade in situ da matéria seca e proteína bruta de diferentes alimentos. In: REUNIÃO ANUAL DA SOCIEDADE BRASILEIRA DE ZOOTECNIA, 34., 1997, Juiz de Fora. Anais... Juiz de Fora: Sociedade Brasileira de Zootecnia, 1997. p.79-81.

MARTINS, S.A., ZEOULA, L.M., PRADO, I.N. et al. Degradação ruminal da matéria seca e proteína bruta de alguns alimentos. In: REUNIÃO ANUAL DA SOCIEDADE BRASILEIRA DE ZOOTECNIA, 35., 1998. Botucatu. Anais... Botucatu: Sociedade Brasileira de Zootecnia, 1998. p.374-376.

MARTÍNEZ, V.L.R. Composição química e degradabilidade in situ de volumosos e concentrados determinada em bubalinos e bovinos. Recife: Universidade Federal Rural de Pernambuco, 1999. 59p. Dissertação (Mestrado em Zootecnia) Universidade Federal Rural de Pernambuco, 1999.

McDONALD, I.W.; HALL, R.J. The conversion of casein into microbial proteins in the rumen. Biochemical Journal, v.67, p.400-405, 1954.

MERTENS, D.R.; LOFTEN, J.R. The effect of starch on forage fiber digestion in vitro. Journal of Dairy Science, v.63, n.9, p.1437-1446, 1980.

MERTENS, D.R. Rate and extent of digestion. In: FORBES, J.M.; FRANCE, J. (Eds.) Quantitative aspects of ruminant digestion and metabolism. England: Commonwealth Agricultural Bureaux, Cambridge University Press, 1993. p.13-51.

MILLER, E.L. Methods of assessing proteins for ruminants including laboratory methods In: MILLER, E.L. (Ed.) Protein contribution of feedstuffs for ruminants Butterwords, Boston, 1982. p.18-32.

MORAIS, P.J. Avaliação do efeito de inoculante bacteriano sobre a qualidade de silagem e desempenho animal. Piracicaba, SP: Escola Superior de Agricultura "Luiz de Queiroz", 1995. 127p. Dissertação (Mestrado em Agronomia) - Escola Superior de Agricultura "Luiz de Queiroz", 1995.

NATIONAL RESEARCH COUNCIL - NRC. Nutrient requirements of dairy cattle. 6.rev.ed. (update 1989). Washington, D.C.: National Academic Press, 1989. 157p.

NATIONAL RESEARCH COUNCIL - NRC. Nutrient requirements of dairy cattle. 7.rev.ed. Washington, D.C.: National Academic Press, 2001. 381p.

NEUTZE, S.A.; SMITH, R.L.; FORBES, W.A. Application of an inhibitor in vitro method for estimating rumen degradation of feed protein. Animal Feed Science and Technology, v.40, n.2, p.251-265, 1993.
OLIVEIRA, L.R. Cinética digestiva em novilhos submetidos a dietas com diferentes níveis de cama de frango e de suplemento à base de microbiota ruminal. Viçosa, MG: Universidade Federal de Viçosa, 1998, 69p. Dissertação (Mestrado em Zootecnia) - Universidade Federal de Viçosa, 1998.

OLIVEIRA, L.R.; PEREIRA, J.C.; SILVA, C.P.R. et al. Degradabilidade ruminal da cama de frango e do feno de capim-coastcross e avaliação de modelos matemáticos para estimativa da taxa de passagem de partículas. Revista Brasileira de Zootecnia, v.28, n.4, p.839-849, 1999.

PINTO, A.A.; LAVEZO, F.J.; CECATO, U. et al. Degradabilidade in situ de cultivares do gênero panicum maximum. In: REUNIÃO ANUAL DA SOCIEDADE BRASILEIRA DE ZOOTECNIA, 35., 1998, Botucatu. Anais... Botucatu: Sociedade Brasileira de Zootecnia, 1998. p.38-40.

RUSSELL, J.B.; SNIFFEN, C.J.; Van SOEST, J.P. Effect of carbohydrate limitation on degradation and utilization of casein by mixed rumen bacteria. Journal of Dairy Science, v.66, n.2, p.763-782, 1983.

SNIFFEN, C.J.; O'CONNOR, J.D.; VAN SOEST, P.J. et al. A net carbohydrate and protein system for evaluating cattle diets: II. Carbohydrate and protein availability. Journal of Animal Science, v.70, n.12, p.3562-3577, 1992.

VALADARES FILHO, S.C. Utilização da técnica in situ para avaliação dos alimentos. In: SIMPÓSIO INTERNACIONAL DE PRODUÇÃO DE RUMINANTES, 1994, Maringá. Anais... Maringá: Sociedade Brasileira de Zootecnia, 1994. p.95-118.

VALADARES FILHO, S.C.; COELHO DA SILVA, J.F.; LEÃO, M.I. et al. Degradabilidade in situ da matérias seca e proteína bruta de vários alimentos em vacas em lactação. Revista da Sociedade Brasileira de Zootecnia, v.19, n.6, p.512-522, 1991.

VALADARES FILHO, S.C.; COELHO DA SILVA, J.F.C.; LEÃO, M.I.. et al. Degradabilidade in situ da proteína bruta e matérias seca de alguns alimentos em vacas gestantes e lactantes. Revista da Sociedade Brasileira de Zootecnia, v.20, n.1, p.111-122, 1990.

VAN SOEST, P.J. Nutritional ecology of the ruminant. New York: Cornell University Press. 1994. 485p.

WARNER, A.C.I. Proteolysis by rumen microorganisms. Journal of Genetic and Microbiology, v.14, n.5, p.749-762, 1956. 